\title{
FEATURES OF USE OF PROFILING TECHNOLOGY AS IDENTIFICATION METHOD
}

\author{
V. Vikhman \\ Novosibirsk State Technical University \\ Novosibirsk, Russian Federation \\ vvv@vt.cs.nstu.ru
}

\author{
G. Rastorguev \\ Novosibirsk State Technical University \\ Novosibirsk, Russian Federation \\ rastorguev@adm.nstu.ru
}

\author{
M. Vilberger \\ Novosibirsk State Technical University \\ Novosibirsk, Russian Federation \\ vilberger@corp.nstu.ru
}

\begin{abstract}
The article presents an analysis of the concept of profiling and its types. It describes the main components and aspects of profiling technology and its applications in different areas of life, particularly in ensuring security in transport, in public life, to prevent offences, commercial and insurance activities, and in personnel management. The need for applying personalization for the purpose of ensuring safety in social systems is grounded. The mechanism of collecting and processing data about the individual and building on their basis of systems for individual identification is described.
\end{abstract}

Keywords_individual behavior; technology; security; criminal; legal actions.

\section{INTRODUCTION}

Profiling is a concept that denotes a set of psychological methods and techniques for assessing and predicting a person's behavior, based on the analysis of the most informative particular characteristics, appearance characteristics, nonverbal and verbal behavior. Profiling technology originated in the late 1970s and began to be used by the Israeli airline El Al. The technology was aimed at reducing the probability of occurrence of risks associated with passengers, and was used during pre-flight inspection. This was a set of issues aimed at identifying non-standard reactions of passengers. This technology used a small set of basic psychological patterns (behavior stereotypes) and more resembled a procedure for psychological testing.

Recently, the expanded interpretation of the profiling concept has included a number of applied socio-psychological techniques; their purpose is to assess the reliability of reported information on the individual non-verbal behavior, i.e. noninstrumental detection of lies. The researches of P. Ekman, V. Frizen, C. Scherer, M. Zuckerman, B. DePaulo, V. Labunskaya, O. Frya and others are the methodological foundations of profiling. Profiling makes us observe and analyze the environment, the behavior of people, look for suspicious signs and establish cause-effect relationships, approach non-standard solutions to problems arising in work more thoughtful. The most controversial aspect of profiling is the so-called ethnic profiling, based on the assumption of a link between the ethnicity of a person and the possibility of illegal behavior. Researches of scientists have established that the verbal component of interpersonal communication is less than $30 \%$, and the nonverbal component makes up more than $70 \%$ of information transmitted during communication. The average person speaks about 10-11 minutes a day, and the average sentence lasts only 2.5 seconds. At the same time, a person can produce and recognize about 250,000 facial expressions [8]. Profiling is a technology to prevent illegal actions by identifying potentially dangerous persons and situations using methods of applied psychology.

Thus, profiling makes it necessary to observe and to analyze the environment and people's behavior more thoughtful, to look for suspicious signs and to establish causeeffect relations, to approach non-standard solutions to the problems, arising in the work. Many years of successful experience with the application of the profiling method abroad and its positive results confirm the practical usefulness of this method in the training of police officers. It can be used in the training of employees of operative-search units, public security police, ATS psychologists, and in a commercial environment in order to minimize the risks of engaging with partners.

Profiling has become increasingly used in the business environment with the development of politics and economics. Separate directions of profiling have appeared. All of them, or rather the training programs and the introduction of profiling systems for companies and individuals, are presented in different variations.

The profiling consists of operative psychodiagnostics, craniofacial profiling, non-instrumental detection of lies, the method of revealing hidden manipulations, graphological analysis. 


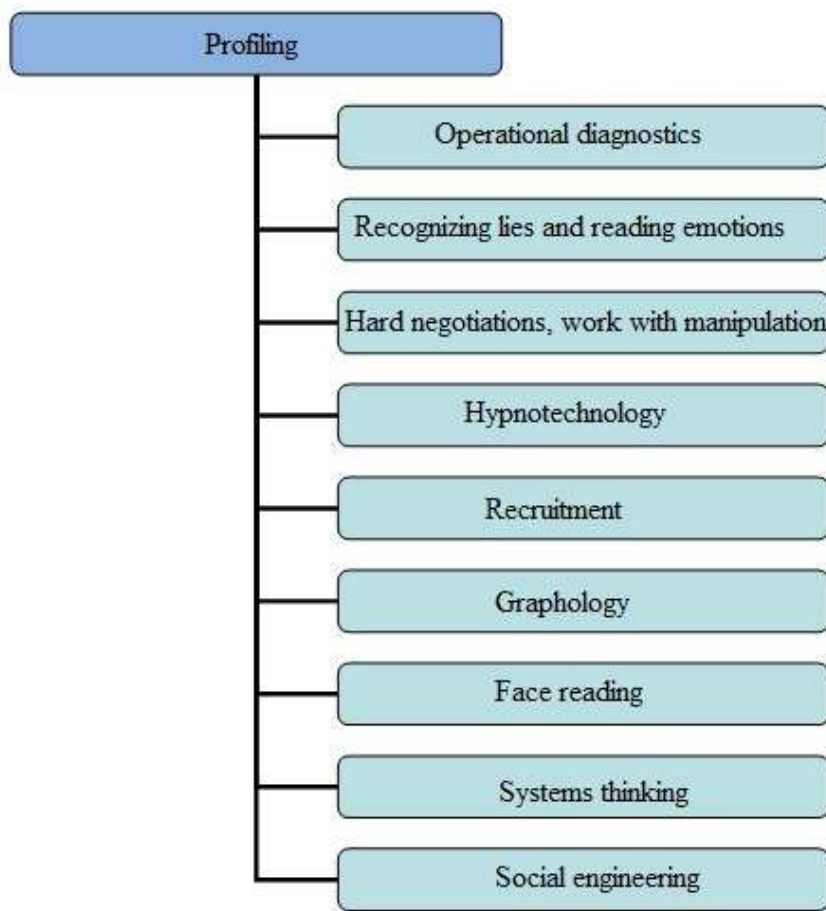

Fig. 1. Types of profiling

\section{The Types Of Profiling AND ItS APPliCATION}

The effectiveness of the profiling technology application depends on the accuracy of its implementation.

The following main stages are distinguished:

1) primary observation of the subject and analysis of the first impression;

2) carrying out various sorts of verification activities (checking documents, inspecting, etc.);

3) conversation with the subject;

4) interrogation of the subject according to established suspicious signs;

5) drawing up the final characteristics of the subject.

Profiling refers a person to a dangerous or non-dangerous type of person depending on the social environment and context. Profiling is basically a technology to prevent illegal actions by identifying potentially dangerous persons and situations using methods of applied psychology and modern IT technologies. The skills of profiling are applicable in various fields of activity; they allow one to significantly reduce the risks associated with the human factor. Training of specialists and raising their level of awareness of risks minimizes the number of incidents.

Depending on the field of application of the profiling, the following types of profiling are distinguished:

-transport (in ensuring transport security);

- profiling during mass events while ensuring the safety of large-scale mass events;
- criminal (in the operational-search activity of the Department of Internal Affairs and forensic psychological examinations in the preparation of a psychological portrait of the criminal);

\section{- Personnel profiling;}

Managerial profiling.

Let us consider each direction in more detail.

\section{IDENTIFICATION OF PERSONALITY IN DIFFERENT PROFILING TECHNOLOGIES}

Modern profiling helps to assess the condition of any person, make up his character profile and give a reliable estimate of what the person says.

\section{A. Transport profiling}

Transport profiling is currently the most developed type and is widely used in the activities of security services, in particular airports, railway and bus stations. The multifacetedness, significance, scale, vulnerability of air transport facilities require the improvement of measures and approaches to ensure their antiterrorist security. A multilevel approach to the implementation of aviation security measures should rely primarily on work with the passenger, and then on the equipment. For example, if a passenger is identified as a threat, then he should be subjected to closer inspection using more personnel and the most complex equipment. For passengers who are supposed to pose less of a threat, standard inspection activities are used. In this regard, for the coordinated, operational work of the services ensuring the safety of passengers, there is a need to create an automated information system to support the operational categorization of air passengers (based on profiling technology). Employees of services, for example, airport security should have basic skills in surveillance and interviewing. These skills are basic and mandatory for the profiler, and in the future, as a necessary constituent element, will be applied to all of the above-mentioned areas of profiling in the activities of aviation security services. The technology of profiling on transport is short-term (related to the massiveness of passenger traffic) and reduced to categorizing the passenger by a certain type, according to the degree of potential danger. The technology of profiling, for example, the airport, is laid as part of the situation center, when categorizing passengers according to the degree of their potential danger [1,2].

Employees of the aviation security service of airports and employees of internal affairs bodies in transport who conduct passenger screening, in accordance with the requirements of the Rules for carrying out preflight and post-flight inspections approved by Order No. 104 of the Ministry of Transport of the Russian Federation of July 25, 2007, are entitled to the following rights:

- to check passengers tickets issued in accordance with the established procedure, and documents proving their identity at the entrance to the points of inspection;

- to conduct a survey to identify potentially dangerous passengers and their things and substances prohibited for air carriage; 
- to carry out searches of passengers, luggage and things held by passengers, crew members of aircraft, civil aviation personnel, airborne aircraft stock, cargo and mail;

- to observe the passengers behavior at the points of inspection.

The introduction of the legal regime of the counterterrorist operation is another important point in the implementation of the profiling in the activities of airport security services and law enforcement agencies in terms of analyzing the overall concept of security in the event of counter-terrorism operations on transport infrastructure facilities and air transport vehicles within the territory of its operation.

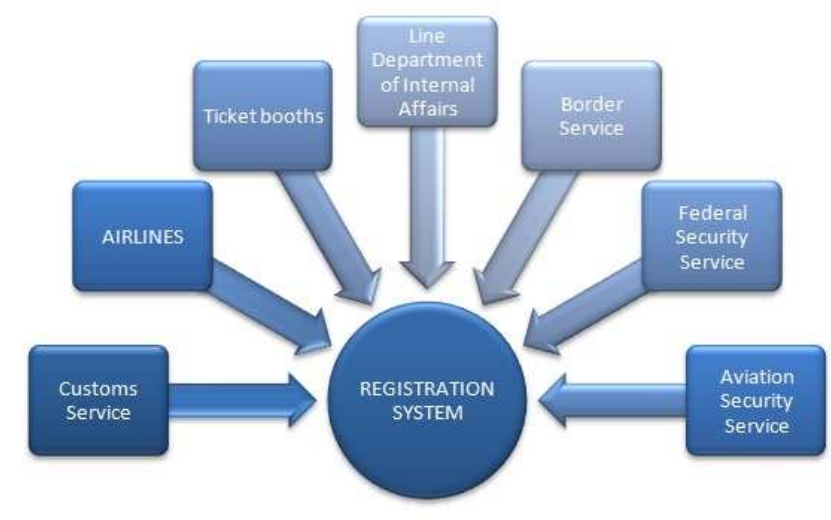

Fig. 2. Security services by the example of the terminal

\section{B. Criminal profiling}

Criminal profiling is divided into subspecies: in the field of operational and official activities and forensic psychological examinations. Initially, the term criminal "profiling" meant the drawing up of a psychological portrait (profile) of the offender in the wake of the crime scene (profiling the person) [3]. The methodology of criminal profiling involves working with the materials of the criminal case and interpreting the evidence. The result of the profiler's work is a criminal profile - a legally significant document that describes the identity and behavior of the offender and the victim in the key of the crime or series of crimes committed [4].

The present paradigm of criminal profiling with its theoretical foundations and methodology has come a long way of becoming and developing. There are several sources of profiling origin: the research of criminologists, specialists in the field of forensic medicine, psychiatrists and criminal psychologists. One of the first attempts to explain the nature of criminal behavior from the standpoint of the biologizational approach belongs to the Italian prison doctor C. Lombroso, who developed an "anthropological" theory of crime. While measuring the anthropological characteristics of the criminals held in prison, he concluded that there are four types of offenders: congenital criminals, passion criminals, accidental criminals and mentally ill criminals. At the same time, "congenital" criminals are characterized by certain somatic features, the structure of the skull, features of the face, due to which they can be recognized in a timely manner and permanently isolated from society or destroyed [2]. Studies of E. Kretschmer showed that there is a high correlation between the structure of the body, the type of personality and the propensity for antisocial behavior. So, he singled out four constitutional types and, as a consequence, the most probable models of wrongful behavior:

- $\quad$ asthenic physique - a tendency to steal and fraud;

- athletic build - a tendency to violent crimes;

- picnic constitution - a tendency to fraud and scam, but violence is possible;

- mixed type - addiction to both crimes against society and violent crimes [2].

G. Gross can be considered the first profiler in the modern sense of the word. He pointed to the possibility of understanding the identity of the criminal through the crime he committed. He offered to investigate crimes based on the fact that any action of a person is a reflection of his personality, thoughts, feelings and life circumstances. Realizing this, one can make up the most complete profile of the criminal and find him [5]. The first person who used the wound pattern analysis method was D. Phillips, who was investigating the case of Jack the Ripper. Examining the bodies of the victims, Phillips concluded that such wounds could be inflicted by a person with medical knowledge and skills. In his opinion, based on the findings of the examination of injuries, it is possible to draw conclusions about the profession, the educational level, hobbies and lifestyle of the offender.

D. Brussel made a significant contribution to the development of profiling methodology.

Types of criminal profiling are systematized as follows:

1) Preventive profiling is reduced to the establishment and criminological analysis of information about certain individuals with the purpose of early prevention of their criminal behavior:

a) insurance profiling helps insurance companies to identify fraudulent schemes when drawing up insurance;

b) hotel profile is aimed at crime prevention. 


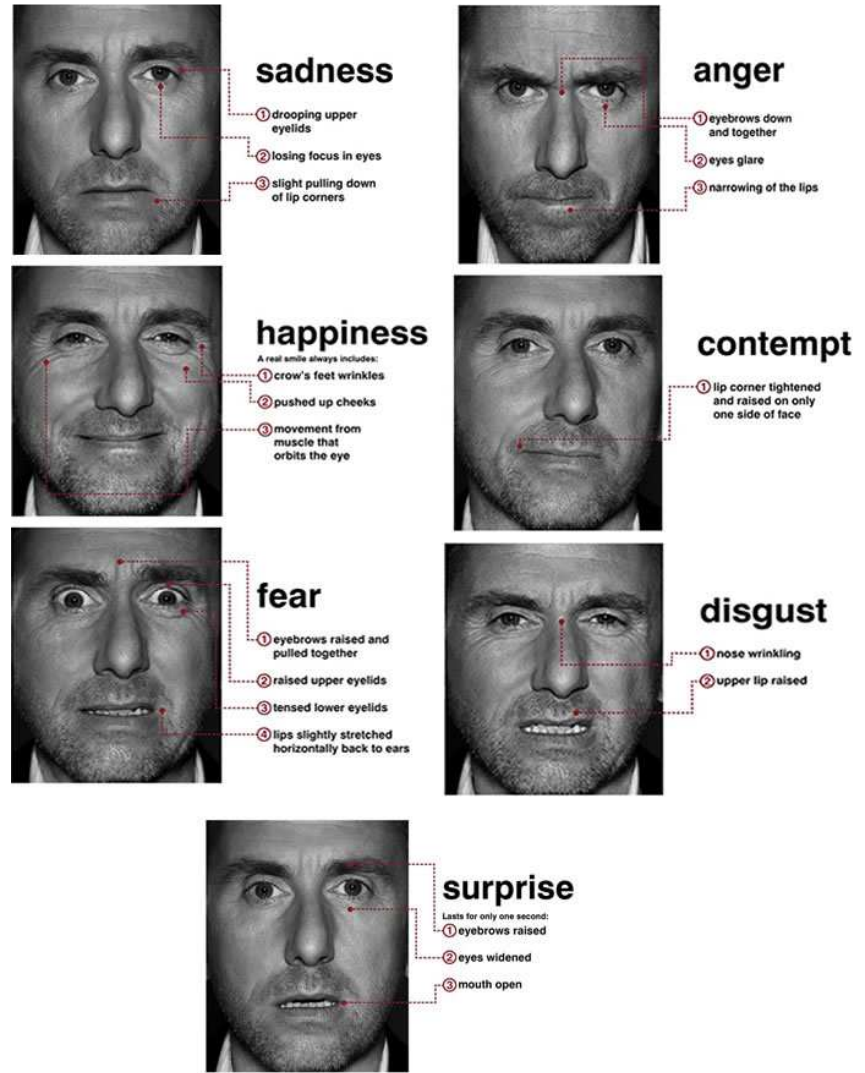

Fig. 3. Basic emotions of the person

2) Prognostic (profile modeling) - assessment of the motivational-dispositional aspect of the personality and predicting human behavior on the basis of analysis of the most informative particular features;

3) Typological - the assignment of a person for some nonverbal signs to personality type: hazardous or non-hazardous, depending on the social environment and the context of the investigation.

4) Operative-search - compiling a psychological search profile (profile) of an unknown person by the tracks at the crime scene;

5) Forensic profiling:

a) non-instrumental detection of lies;

b) an estimation of reliability of the information reported by the person on its non-verbal behavior;

c) tactical;

d) construction of an investigative strategy based on the constructed personality profile;

e) victimological profiling - drawing a portrait of a victim, or a potential victim.

\section{Personnel profiling}

Personnel profiling is divided into psycho-diagnostic work and professional-psychological training. Its main purpose is to establish the compliance of applicants with the requirements set by the employer. With this check, the main advantage of the profiler is to reliably determine the candidate's negative habits and addictions, criminal past, the desire to commit misconduct, without exposing the test subject to control on a polygraph. At the same time, the personnel profile is one of the important tools for effective formation of the personnel reserve with subsequent appointment to the posts. In this case, profiling involves not only the establishment of true information provided by the candidate, but also determines his characterological specificities, the leading psychotype with the basic emotion, the metaprogramme profile, the most frequently used focuses of the language, the archetype. Personnel profiling and operational psychodiagnostics of personality help to predict the future behavior of a candidate for a position in a particular firm, a company with a high degree of probability, as shown by the application of this technology to various enterprises, organizations and institutions [7].

In the personnel profiling, dynamic profiling is highlighted. Knowing the profile of the position, or more exactly what tasks a particular employee should perform in his / her activity, the profiler forms the psychological profile of the necessary employees and, at the same time, necessarily takes into account the possibility of their symbiosis with their characterological differences. After that, the candidates corresponding to the profile are selected. Later, a dynamic profiling begins to work, it helps to clearly understand which employee and how to motivate, how to manage it, how he will behave in stress or conflict situations. Forming a picture of structurally dynamic profiling for each department and the company as a whole helps to manage the team as a ship, turning at the right moment where one needs, and while realizing that the ship will be intact and its speed will increase, although the energy costs may decrease. This is the employee management system, which brings the maximum return to the business. Psychological methods of employee management can be limited to effective application of dynamic profiling, and then growth and development will not be long in coming. After all, the ability to lead a team, to manage it effectively and to use human resources correctly were the main skills of Steve Jobs. 


\begin{tabular}{|c|c|c|c|}
\hline \multicolumn{2}{|c|}{ Extrovert } & \multicolumn{2}{|c|}{ Introvert } \\
\hline Choleric & Sanguine & Phlegmatic & Melancholic \\
\hline $\begin{array}{l}\text { Impulsive } \\
\text { Highly emotional } \\
\text { Affective } \\
\text { Badly controls the } \\
\text { feelings } \\
\text { Touchy } \\
\text { Conflict } \\
\text { The long-winded } \\
\text { Fussy } \\
\text { Communicative } \\
\text { Expansive }\end{array}$ & $\begin{array}{c}\text { Communicative } \\
\text { Balanced } \\
\text { With a constantly even } \\
\text { good mood } \\
\text { Capable of quick } \\
\text { emotional and } \\
\text { intelligent switching } \\
\text { Easy to contact } \\
\text { "Sunny" person }\end{array}$ & $\begin{array}{c}\text { Balanced } \\
\text { Calm } \\
\text { Closed } \\
\text { Peaceful } \\
\text { Unemotional } \\
\text { Reliable } \\
\text { Slow } \\
\text { Selective in contacts } \\
\text { Non-Initiative }\end{array}$ & $\begin{array}{l}\text { Vulnerable } \\
\text { Sensitive } \\
\text { Impressionable } \\
\text { Irritable } \\
\text { Delicate } \\
\text { Vocal and } \\
\text { expressively reserved } \\
\text { Shy } \\
\text { Indecisive } \\
\text { Closed } \\
\text { Anxious } \\
\text { Inclined to self- } \\
\text { examination }\end{array}$ \\
\hline
\end{tabular}

Fig. 4. Psychological portrait of personality

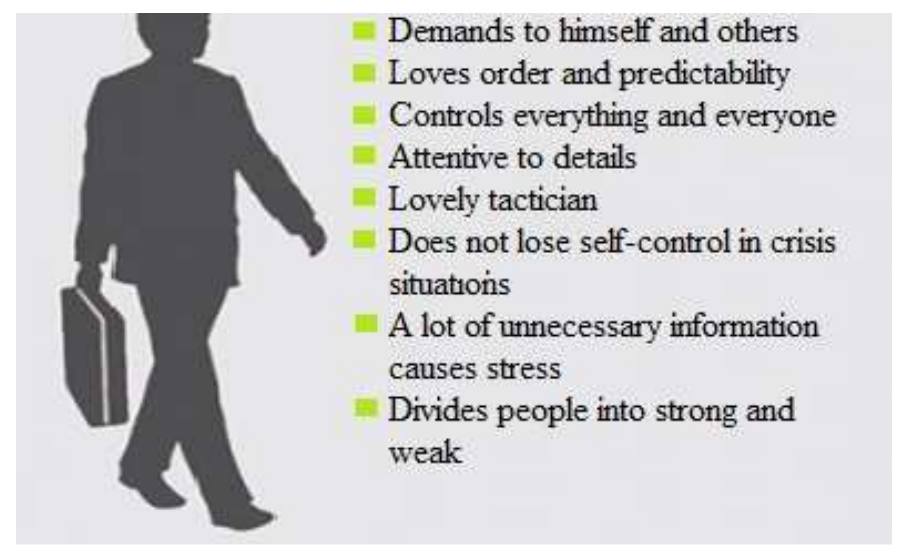

Fig. 5. Personnel profile: executive (epileptoid) employee

\section{Managerial profiling}

The selection of personnel goes beyond the traditional management and its content includes methods and technologies that allow solving the tasks of staffing professional activity, being introduced into the management process, qualitatively influencing the result. In the field of personnel management, different tests using objective methods and techniques are the most popular in psychodiagnostic work with candidates for the post [6]. Profiling technology is indispensable in the field of personnel management and is a tool for investigating and analyzing the reliability of the information reported during performing personnel checks and interviews.
Application of verification technologies and profiling is a powerful tool for psychodiagnostic work. They are indispensable in the field of personnel management and represent, in the authors' opinion, the most successful tool for investigating and analyzing the reliability of the information reported during carrying out personnel checks and interviews. Verification is the work with the available data, and profiling is the compilation of the psychological profile of the person being examined (the interviewee, the candidate for the position). The verification and profiling technologies allow the managers and employees of the company's HR departments to quickly assess the psychological profile of the individual, identify and analyze the hierarchical structure of its values, focus and motivation, habits, attitudes and beliefs, goals and behavioral patterns.

\section{CONCLUSION}

Thus, at present, the analysis of technologies for identifying individuals and designing complex methods based on a specific sphere of human activity is an urgent task. These problems are the starting point for creating a universal technological solution. Further study of profiling techniques will be the basis for building a new methodology and technology for managing the situation using psychological and social techniques.

\section{References}

[1] B. Wichmann, "Development of algorithmic support of automated control system of categorization passengers," Scientific Bulletin of NSTU, Novosibirsk. State. Tech. University, № 3(24), pp. 179-185, 2006.

[2] B. Wichmann, "The Design of integrated automated system of monitoring of the potential dangers of passengers on the basis of the IAD," Scientific Bulletin of NSTU, Novosibirsk. State. Tech. University, № 2(23), Pp. 167-172, 2006.

[3] S. Jicinska, Profiling as a method kriminological examination, No. 4-1: The Genesis of Genius, 2015, pp. 134-137.

[4] V. Kudin, V. Statniy, "Profiling in the internal Affairs bodies: from theory to practice and methodology", vol. 3 (59), pp. 4-15, 2013

[5] A. Kosolapov, A. Kuvshinov, A. Nyrkov, A. tashlinskiy, S., Kravchuk, I. Maltseva, S. Voronov, D. mikhalevskijj, D. Minochkin, A. prokhorenkov, A. Sova, S. Sokolov, A. Florensov, Vol. Knysh, V. Vorontsov, A. Nikiforov, A. Ovseichik, M. Pankov, Information and communication technologies, Odessa, 2015.

[6] O. vikhansky, Strategic management, Tutorial, Moscow: Gardarika, 2005, pp. 270-296.

[7] S. Barkova, Personnel Management, Novosibirsk, 2001, p. 46.

[8] A. Kozuleva, "Approaches to Understanding of Lie and its Display at a Psychophysical, Psychological and Socially-psychological Level of Functioning of Mentality", Siberian law Bulletin, vol. 3, pp. 67-74, 2009. 